\title{
RELAÇÃO ENTRE ATRIBUTOS FÍSICOS E QUÍMICOS DOS SOLOS E A PRODUTIVIDADE DE CAPIM DOURADO NA REGIÃO DO JALAPÃO, TO
}

\author{
Helena Maria de Paula Santana ${ }^{(1)}$, Edson Eyji Sano(2), Manuel Pereira de Oliveira Júnior ${ }^{(3)}$, \\ Marilusa Pinto Coelho Lacerda ${ }^{(4) *}$ e Juaci Vitoria Malaquias ${ }^{(2)}$
}

\footnotetext{
(1) Instituto Natureza do Tocantins, Diretoria de Monitoramento Ambiental, Palmas, Tocantins, Brasil.

(2) Empresa Brasileira de Pesquisa Agropecuária, Centro Nacional de Pesquisa do Cerrado, Planaltina, Distrito Federal, Brasil.

(3) Universidade de Brasília, Faculdade de Agronomia e Veterinária, Programa de Pós-graduação em Agronomia, Brasília, Distrito Federal, Brasil.

(4) Universidade de Brasília, Faculdade de Agronomia e Veterinária, Brasília, Distrito Federal, Brasil.

* Autor correspondente.

E-mail: marilusa@unb.br
}

\begin{abstract}
RESUMO
Na região do Jalapão, no Estado do Tocantins, existem grandes áreas contínuas de Neossolos Quartzarênicos, com desenvolvimento do capim dourado (Syngonanthus nitens), espécie nativa utilizada na confecção de artesanatos nessa região, possuindo destacada importância na economia local. O objetivo deste estudo foi verificar a relação entre os atributos físicos e químicos dos solos e a produtividade de capim dourado nos Campos Limpos Úmidos associados às Veredas no Parque Estadual do Jalapão. Foram coletadas amostras de solo e escapos de capim dourado e realizadas medições de declividade do terreno ao longo de caminhamento ou transeções perpendiculares às linhas de drenagem das Veredas selecionadas para o estudo. Foram identificados três tipos principais de solos ao longo das transeções: Neossolo Quartzarênico órtico típico, Neossolo Quartzarênico hidromórfico típico e Organossolo Háplico fíbrico típico. A produtividade de capim dourado foi analisada por meio de modelos de regressão múltipla, envolvendo 26 variáveis dos solos. Em razão da significância, o modelo final ficou constituído por seis dessas variáveis: $\mathbf{p H}, \mathrm{Mg}^{2+}, \mathrm{Ca}^{2+}$, areia fina, argila e umidade do solo. $O$ modelo de regressão quadrática múltipla envolvendo essas seis variáveis contemplou $R^{2}$ de 0,85 e $R^{2}$ ajustado de 0,81 da relação avaliada, onde a umidade dos solos foi a variável mais importante.
\end{abstract}

Palavras-chave: Syngonanthus nitens, vereda, regressão múltipla, solos arenosos. 


\title{
ABSTRACT: RELATIONSHIP BETWEEN SOIL PHYSICAL AND CHEMICAL PROPERTIES AND YIELD OF GOLDEN GRASS IN THE JALAPÃO REGION, TO, BRAZIL
}

\begin{abstract}
In the Jalapão region, State of Tocantins, Brazil, there are large contiguous areas of Neossolos Quartzarênicos (Tropsamments). Golden grass (Syngonanthus nitens) is a native species widely used as material for handicrafts in the region, and it is therefore of great importance for the local economy. The aim of this study was to analyze the relationship between soil physical and chemical properties and golden grass yield in Campos Limpos Úmidos within Jalapão State Park (Parque Estadual do Jalapão). We collected soil samples and golden grass scapes and made slope measurements along the transects perpendicular to the drainage lines. We identified three soil units: Neossolo Quartzarênico órtico típico, Neossolo Quartzarênico hidromórfico típico, and Organossolo Háplico fíbrico típico (Orthpsamment, Hydropsamment, and Hydrofibrist, respectively). Multiple regression models involving 26 variables further portrayed golden grass yield. Six of these variables subsequently proved to be of greatest significance and constituted the final model: $\mathrm{pH}, \mathrm{Mg}^{2+}, \mathrm{Ca}^{2+}$, fine sand, clay, and soil moisture. The multiple quadratic regression model involving these six variables considered an $R^{2}$ of 0.85 (adjusted $R^{2}$ of 0.81 ) of the relationship evaluated. Soil moisture was the most important variable.
\end{abstract}

Keywords: Syngonanthus nitens, multivariate regression, sandy soils.

\section{INTRODUÇÃO}

Os Neossolos Quartzarênicos (RQ) ocupam 30 milhões de hectares no bioma Cerrado (Caetano et al., 2013); no entanto, observam-se poucos estudos envolvendo a caracterização desses solos sob ambientes nativos. No Estado do Tocantins, os RQ ocupam aproximadamente 18,52 \% do seu território (Seplan, 2012).

Na região do Jalapão, Estado do Tocantins, ocorrem grandes áreas contínuas com desenvolvimento de $\mathrm{RQ}$, que apresentam intensa rede de drenagem e por causa das características físicas e químicas dessa classe de solo, além do relevo plano, ocorre o desenvolvimento de Campos Limpos Úmidos (Santana et al., 2014). A cobertura vegetal natural na região encontra-se preservada (Santiago e Pereira Júnior, 2010), ou seja, verifica-se baixa conversão da vegetação natural em uso antrópico. Em razão dessa preservação, da riqueza em biodiversidade, das limitações do uso agrícola, das fragilidades dessa classe de solo, entre outras variáveis, foram criadas diversas unidades de conservação, o que torna a região um local propício para pesquisas com espécies de ocorrências naturais do Cerrado.

Nos locais onde os RQ predominam, na região do Jalapão, destaca-se o extrativismo do capim dourado, Syngonanthus nitens (Bong.) Ruhland, da família Eriocaulaceae. O capim dourado é uma sempre-viva, ou seja, mantém a forma e a coloração dos escapos e as inflorescências inalteradas após serem coletados, como se tais estruturas estivessem vivas (Giulietti et al., 1996); essas características fazem dessa espécie a matéria-prima para a produção de artesanato. Além da ocorrência do capim dourado nos Campos Limpos Úmidos da região do Jalapão, TO (Schmidt et al., 2007; Schmidt e Ticktin, 2012; Santana et al., 2014), a ocorrência dessa espécie ainda é relatada na Chapada dos Veadeiros, GO, no Distrito Federal (Munhoz e Felfili, 2007) e no Triângulo Mineiro, MG (Ramos et al., 2006), e está sempre associada à fitofisionomia de Veredas. De acordo com Carvalho (1991), as Veredas constituem subsistemas úmidos que participam do controle do fluxo do lençol freático, desempenhando papel fundamental no equilíbrio hidrológico dos cursos d'água no ambiente do Cerrado. Schmidt e Ticktin (2012), Pacifico et al. (2011), Schmidt et al. (2011) caracterizaram o capim dourado como um importante produto de exploração não florestal, no ambiente de Veredas na região do Jalapão.

Estudos relacionados à produtividade vegetal e aos atributos físicos ou químicos do solo são comuns em espécies cultivadas; entretanto, tais estudos em espécies de ocorrência natural são pouco comuns, em razão principalmente ao grau de dispersão das espécies que ocorrem em mosaicos vegetacionais, como acontece no bioma Cerrado, sem que haja padrão definido de ocorrência da espécie. Os estudos de produtividade em espécies de ocorrência natural no Cerrado têm-se concentrado nas espécies frutíferas, tanto para consumo in natura como para industrialização; são os casos do baru (Dipteryx alata) (Sano e Simon, 2008) e do araticum (Annona spp.) (Mesquita et al., 2007), entre outros.

Diante do exposto, este trabalho teve como objetivo verificar a relação entre os atributos físicos e químicos dos solos e a produtividade de capim dourado nos Campos Limpos Úmidos associados às Veredas no Parque Estadual do Jalapão, TO.

\section{MATERIAL E MÉTODOS}

A área de estudo situa-se no Parque Estadual do Jalapão (PEJ), no município de Mateiros, TO, 
entre as latitudes $10^{\circ} 08^{\prime} 73^{\prime \prime} \mathrm{S}$ e $10^{\circ} 35^{\prime} 09^{\prime \prime} \mathrm{S}$ e as longitudes $47^{\circ} 04^{\prime} 01^{\prime \prime} \mathrm{W}$ e $47^{\circ} 35^{\prime} 06^{\prime}$ ' W. O PEJ foi criado pela Lei Estadual $n^{\circ}$. 1.203, de 12 de janeiro de 2001, possui 158.885 ha e ocupa $16 \%$ da área municipal de Mateiros. No interior do PEJ, ocorrem várias nascentes que alimentam a bacia do rio Sono e o sistema hidrográfico Tocantins-Araguaia. $\mathrm{O}$ relevo dominante é plano a suave ondulado, com altitudes variando de 400 a $500 \mathrm{~m}$. Destacam-se as escarpas erosivas representadas pelas serras do Espírito Santo, Jalapinha e Porco, que atingem altitudes entre 770 e $798 \mathrm{~m}$. Quanto aos solos da região, predominam os Neossolos Quartzarênicos órticos, originados de rochas sedimentares areníticas do Grupo Urucuia (Seplan, 2012).

O PEJ abriga diferentes formações vegetacionais savânicas, com predominância de espécies campestres (Sano et al., 2008; Santiago e Pereira Júnior, 2010). O clima na região, segundo o critério de Thornthwaite, é classificado como C1dA'a', que corresponde a clima subúmido seco com moderada deficiência hídrica no inverno e precipitação pluvial média anual entre 1.500 e $1.600 \mathrm{~mm}$. O período chuvoso compreende os meses de novembro a abril, enquanto o período de seca inicia-se em maio, terminando em outubro. A temperatura média anual é de $27^{\circ} \mathrm{C}$ (Seplan, 2012).

Para o estudo, foram selecionadas 10 Veredas no PEJ, consideradas representativas do Parque em relação às suas dimensões e proporção das suas áreas de inundação, proporcionando o desenvolvimento de classes de solos similares e ocorrência de vegetação nativa preservada com ocorrência do capim dourado. Essas informações foram extraídas por meio de análises prévias em fotografias aéreas, na escala de 1:25.000, obtidas em novembro de 2002 pelo Projeto AASA 92/02 (Naturatins, 2002) e de imagens do satélite RapidEye de 16 de setembro e 14 de outubro de 2010, utilizadas por Santana et al. (2014).

Como o mês de setembro representa a época em que o capim dourado atinge a plena maturação (Naturatins, 2007), as campanhas de campo para a coleta de amostras para este estudo foram realizadas de 27 agosto a $1^{\circ}$ de setembro de 2011 , período sem precipitação pluvial. Durante as atividades de campo, foram coletadas amostras de solos, de capim dourado, além de medições de declividades dos terrenos ocupados pelos Campos Limpos Úmidos associados às Veredas avaliadas.

Para a amostragem, nas Veredas selecionadas para o estudo, foram estabelecidos três caminhamentos ou transeções perpendiculares às linhas de drenagem, com $100 \mathrm{~m}$ de espaçamento entre elas. As transeções partiam-se das áreas mais afastadas da rede de drenagem, onde se verificava o início da ocorrência de Campos Limpos Úmidos, até as proximidades da área inundada, próxima à rede de drenagem, marcada pela presença da palmácea buriti (Mauritia flexuosa).

As transeções foram divididas em três segmentos de mesma extensão em relação ao maior comprimento de cada uma delas, denominadas de $\mathrm{S} 1$ (segmento mais afastado da rede de drenagem, com ocorrência de solos mais secos), S2 (segmento intermediário, com solos com umidade intermediária) e S3 (segmento próximo à rede de drenagem, com solos mais úmidos), como demonstrado na figura 1.

Em cada segmento, foram coletadas amostras indeformadas e deformadas de solos na profundidade de $0-10 \mathrm{~cm}$, ambas com três repetições; amostras aleatórias da população de capim dourado em uma área de $0,5 \times 0,5 \mathrm{~m}$, com três repetições. Foram feitas leituras de diferença de nível para estimar a declividade

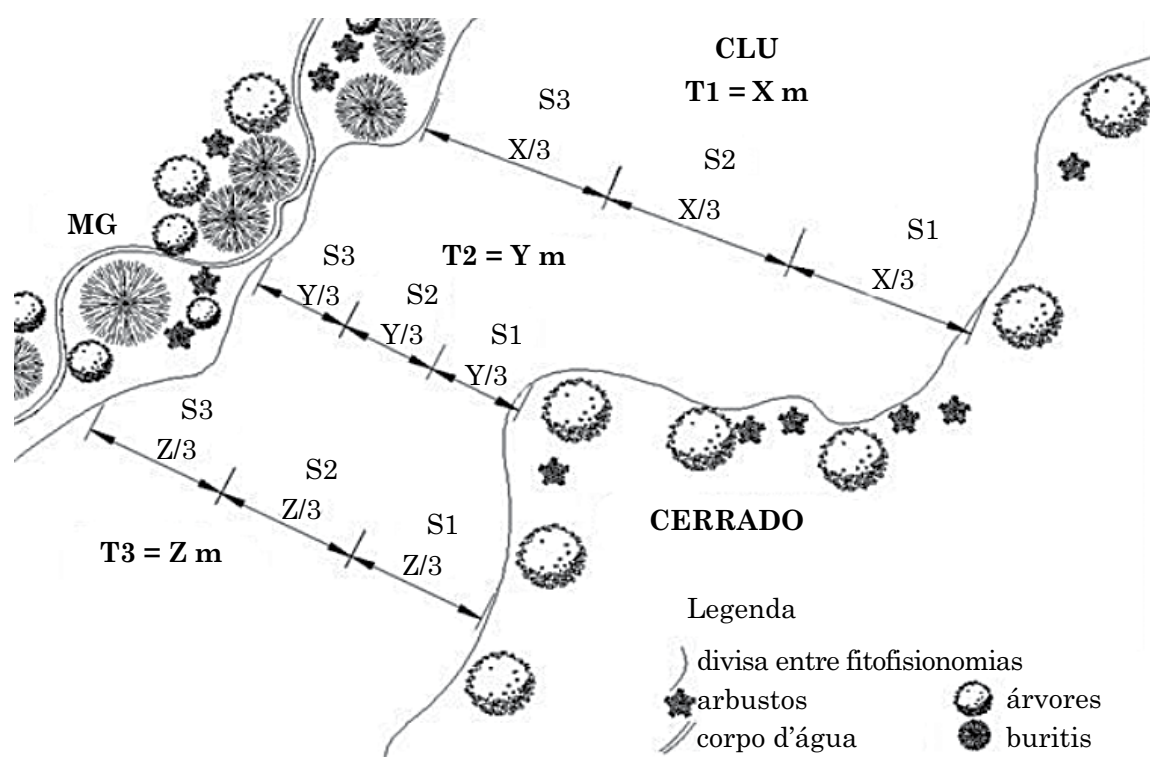

Figura 1. Esquema amostral de solos, capim dourado e de medições de declividade do terreno nas Veredas selecionadas para o estudo. T: transeções; S: segmentos; MG: mata de galeria; e CLU: campo limpo úmido. 
do terreno, utilizando-se de uma mangueira de plástico transparente (Guimarães et al., 2002), anotando-se a diferença de cota a cada posição no terreno no sentido de S1 para S3. Assim, ao final da amostragem, para as 10 Veredas selecionadas totalizaram-se 90 amostras de solos (deformadas e indeformadas), 90 amostras de capim dourado e 90 medições de declividade (três transeções $\times$ três segmentos).

Com as amostras indeformadas dos solos, determinaram-se a umidade volumétrica e densidade dos solos (Ds). As amostras deformadas foram secas ao ar, destorroadas e passadas em peneiras de malha de $2 \mathrm{~mm}$, para obter a fração terra fina seca ao ar (TFSA). Com essas amostras, foram realizadas análises granulométricas (areia fina, areia grossa, areia total, argila e silte) e químicas. As análises químicas constaram de determinações de $\mathrm{pH}$ em água; acidez potencial $(\mathrm{H}+\mathrm{Al})$ (Acetato de cálcio $0,5 \mathrm{~mol} \mathrm{~L}^{-1}$, pH 7,0); P e K (extrator Mehlich-1); $\mathrm{Ca}^{2+}{\mathrm{e} \mathrm{Mg}^{2+}}^{2+}$ (KCl $\left.1 \mathrm{~mol} \mathrm{~L}^{-1}\right)$. A matéria orgânica (MO) foi extraída por via úmida pelo método Walkey-Black e o carbono orgânico (CO) foi obtido pelo equivalente de 58 \% da MO. Foram calculados os valores de somas de bases (S); capacidade de troca catiônica (CTC) (T); CTC efetiva (t); saturação por bases (V) e saturação por alumínio (m), por meio das amostras deformadas. As análises físicas e químicas dos solos seguiram métodos descritos em Embrapa (1997). Todas as análises laboratoriais de solos foram realizadas nos Laboratórios de Física e Química de Solos da Embrapa Cerrados.

Os escapos coletados de capim dourado foram acondicionados em sacos de papel e posteriormente foram encaminhados ao laboratório, onde foram secos em estufa de circulação forçada de ar a uma temperatura de $55^{\circ} \mathrm{C}$ por $48 \mathrm{~h}$ ou até peso constante. Em seguida, foram pesados em balança analítica de precisão (quatro casas decimais) no Laboratório de Física de Solos da Embrapa Cerrados.

Dessa forma, foram avaliadas 23 variáveis envolvendo atributos físicos e químicos dos solos e declividade do terreno. De posse desses dados, foi criada uma matriz de dados com as variáveis analisadas mais três variáveis categóricas (segmentos 1, 2 e 3), para investigar e modelar a relação entre produtividade de escapos de capim dourado (variável dependente) e as variáveis estudadas consideradas independentes, utilizando a análise de regressão linear múltipla.

Para realizar as análises estatísticas, foi utilizado o Statistical Package for Social Sciences (SPSS), versão 19.0 (SPSS, 2008), em que as variáveis independentes utilizadas para a construção do modelo foram selecionadas pelo procedimento backward disponível nesse programa. Neste estudo, foi ajustado um modelo de regressão polinomial múltipla de segunda ordem, também chamado de regressão quadrática múltipla.

Para definir o modelo, visto que os resultados das variáveis independentes analisadas evidenciaram pequena variação, para cada segmento das transeções foi realizada a média aritmética dos dados. Com isso, reduziu-se o número de amostras de solos, do capim dourado e da declividade de 90 para 30. Utilizou-se a transformação logarítmica da variável dependente $Y$ e estabeleceu-se nova variável dependente $\ln \left(\mathrm{Y}_{\mathrm{j}}\right)$, que corresponde ao "logaritmo natural de $\mathrm{Y}+1$ ", a fim de reduzir a assimetria da distribuição e aproximar sua curvatura da distribuição normal. Essa transformação foi utilizada, ainda, para reduzir o problema da heterocedasticidade, ou seja, a distribuição desigual das variâncias dos erros aleatórios da função de regressão, procedimento semelhante ao realizado por Lúcio et al. (2010, 2011), com o diferencial que os autores usaram transformação $\lambda y=\ln (x+0,5)$.

Foi realizada ainda uma análise exploratória para verificar a existência de possíveis valores atípicos (outliers) por meio dos resíduos padronizados maiores que +2 ou menores que -2 . A existência de tais dados pode distorcer os resultados do estudo; logo, a sua presença deve ser verificada, identificada e desconsiderada na análise. A análise de variância foi utilizada para avaliar o modelo de regressão linear múltipla pelo método dos mínimos quadrados. $\mathrm{O}$ teste $\mathrm{t}$ avaliou a significância estatística dos coeficientes de regressão estimados para as variáveis independentes em nível de significância de $5 \%$. A análise de multicolinearidade foi avaliada no modelo de regressão para verificar a correlação entre duas ou mais variáveis independentes ou entre uma delas e as demais incluídas no modelo, pelo fator de inflação da variância (Mayers, 2000).

Com esses procedimentos, foram avaliados os quatro pressupostos para a regressão (linearidade, independência dos erros, normalidade dos erros e igualdade de variâncias) para verificar a existência de comportamento linear entre as variáveis, a existência de homocedasticidade nos dados, a distribuição normal dos resíduos, a multicolinearidade das variáveis e a ocorrência de outliers.

Para avaliar o grau de desvio do modelo, em relação à linha de ajuste perfeito (linha 1:1), foi utilizado o recurso da regressão linear simples, aplicado aos pares dos valores estimado e observado. A qualidade preditiva do modelo foi avaliada quanto à precisão, à exatidão e ao desempenho. A precisão foi avaliada pelo coeficiente de correlação de Pearson (r) entre a produtividade observada e a estimada, indicando o grau de dispersão dos dados obtidos em relação à média, ou seja, o erro aleatório. A exatidão foi quantificada pelo índice de concordância (d) de Willmott (Willmott, 1982). Essa exatidão está relacionada ao afastamento dos valores estimados em relação aos observados. Seus valores variam de zero (nenhuma concordância) a 1 (concordância perfeita). O desempenho do modelo foi quantificado pelo índice de consistência $\mathrm{c}=\mathrm{r} \times \mathrm{d}$ (Camargo e Sentelhas, 1997), que, de acordo com os critérios de interpretação proposto pelos autores, o índice c varia 
de zero a 1 , correspondendo a desempenho péssimo a ótimo, respectivamente.

\section{RESULTADOS E DISCUSSÃO}

\section{Segmento S1 das transeções}

Os solos desse segmento apresentaram textura arenosa 988,68 $\mathrm{g} \mathrm{kg}^{-1}$ de areia total e $11,31 \mathrm{~g} \mathrm{~kg}^{-1}$ de soma dos teores de argila e silte, representando solos com grãos simples, sem estruturação (Quadro 1). Santana et al. (2010) encontraram valores de 896,70 $\mathrm{g} \mathrm{kg}^{-1}$ de areia total e a soma dos teores de argila e silte com 103,30 $\mathrm{g} \mathrm{kg}^{-1}$, em RQ no município de Lagoa do Tocantins, região do Jalapão. Nesse segmento, os solos foram classificados como Neossolos Quartzarênicos órticos típicos, segundo o Sistema Brasileiro de Classificação de Solos (Embrapa, 2013).

Nesse segmento, foi encontrado o menor teor de água no solo $\left(0,03 \mathrm{~cm}^{3} \mathrm{~cm}^{-3}\right)$. A Ds foi a mais alta em relação aos demais segmentos, com valor médio de $1,49 \mathrm{~kg} \mathrm{dm}^{-3}$. Já o teor de carbono orgânico (CO) foi o menor, com 4,01 $\mathrm{g} \mathrm{kg}^{-1}$. O baixo teor de $\mathrm{CO}$ ocorreu em razão da constituição mineral arenosa dos solos, com baixa CTC, que confere baixa fixação da matéria orgânica, além da elevada temperatura média anual da região $\left(27^{\circ} \mathrm{C}\right)$, que também contribui para elevadas taxas de oxidação biológica do $\mathrm{CO}$ do solo (Bayer et al., 2000). Santana et al. (2010) também encontraram baixos teores de CO em RQ na região do Jalapão, onde os teores de MO variaram de 6,57 a 7,69 $\mathrm{g} \mathrm{kg}^{-1}$. Carbono orgânico, $\mathrm{S}, \mathrm{Al}^{3+}$, acidez potencial $(\mathrm{H}+\mathrm{Al})$ e, consequentemente, valores de $\mathrm{T}$ e CTC efetiva apresentaram menores valores em relação aos demais segmentos. Os solos desse segmento apresentaram baixo $\mathrm{pH}$, classificando-se como medianamente ácido.

Em relação à declividade, não foram verificadas grandes amplitudes entre S1 e S3. A média variou de 5,27 a $5,42 \%$, classificando-se o relevo como suave ondulado.

Quadro 1. Média das análises físicas e químicas dos solos, declividade do terreno e produtividade de capim dourado dos segmentos S1, S2 e S3 das Veredas avaliadas no PEJ

\begin{tabular}{|c|c|c|c|}
\hline Atributo & Segmento 1 & Segmento 2 & Segmento 3 \\
\hline $\operatorname{Argila}\left(\mathrm{g} \mathrm{kg}^{-1}\right)^{(1)}$ & 4,66 & 29,66 & 95,33 \\
\hline Silte $\left(\mathrm{g} \mathrm{kg}^{-1}\right)^{(1)}$ & 6,66 & 24,33 & 109,66 \\
\hline Areia grossa $\left(\mathrm{g} \mathrm{kg}^{-1}\right)^{(1)}$ & 439,33 & 473,33 & 273,66 \\
\hline Areia fina $\left(\mathrm{g} \mathrm{kg}^{-1}\right)^{(1)}$ & 549,33 & 472,66 & 521,33 \\
\hline Areia total $\left(\mathrm{g} \mathrm{kg}^{-1}\right)^{(1)}$ & 988,66 & 945,99 & 794,99 \\
\hline Densidade do solo - Ds $\left(\mathrm{kg} \mathrm{dm}^{-3}\right)^{(2)}$ & 1,49 & 1,09 & 0,33 \\
\hline Umidade $\left(\mathrm{cm}^{3} \mathrm{~cm}^{-3}\right)^{(2)}$ & 0,03 & 0,40 & 0,73 \\
\hline Declividade (\%) & 5,27 & 5,36 & 5,42 \\
\hline $\mathrm{pH}\left(\mathrm{H}_{2} \mathrm{O}\right)^{(3)}$ & 5,52 & 5,47 & 5,22 \\
\hline $\mathrm{K}^{+}\left(\mathrm{cmol}_{\mathrm{c}} \mathrm{dm}^{-3}\right)^{(4)}$ & 0,01 & 0,04 & 0,11 \\
\hline $\mathrm{Mg}^{2+}\left(\mathrm{cmol}_{\mathrm{c}} \mathrm{dm}^{-3}\right)^{(5)}$ & 0,32 & 0,35 & 0,37 \\
\hline $\mathrm{Ca}^{2+}\left(\mathrm{cmol}_{\mathrm{c}} \mathrm{dm}^{-3}\right)^{(5)}$ & 0,11 & 0,12 & 0,16 \\
\hline $\mathrm{Al}^{3+}\left(\mathrm{cmol}_{\mathrm{c}} \mathrm{dm}^{-3}\right)^{(5)}$ & 0,47 & 1,02 & 1,77 \\
\hline $\mathrm{H}+\mathrm{Al}\left(\mathrm{cmol}_{\mathrm{c}} \mathrm{dm}^{-3}\right)^{(6)}$ & 2,75 & 6,69 & 12,98 \\
\hline $\mathrm{P}\left(\mathrm{mg} \mathrm{kg}^{-1}\right)^{(4)}$ & 1,36 & 1,71 & 4,31 \\
\hline Soma de bases - S $\left(\mathrm{cmol}_{\mathrm{c}} \mathrm{dm}^{-3}\right)$ & 0,44 & 0,52 & 0,64 \\
\hline CTC efetiva - t $\left(\mathrm{cmol}_{\mathrm{c}} \mathrm{dm}^{-3}\right)$ & 0,91 & 1,52 & 2,42 \\
\hline CTC a pH $7-\mathrm{T}\left(\mathrm{cmol}_{\mathrm{c}} \mathrm{dm}^{-3}\right)$ & 3,19 & 7,21 & 13,63 \\
\hline Saturação por Al - m (\%) & 51,53 & 63,10 & 72,85 \\
\hline Saturação por bases - V (\%) & 14,72 & 9,05 & 4,99 \\
\hline Carbono orgânico - CO $\left(\mathrm{g} \mathrm{kg}^{-1}\right)^{(7)}$ & 6,91 & 46,08 & 195,06 \\
\hline Matéria orgânica - MO $\left(\mathrm{g} \mathrm{kg}^{-1}\right)$ & 4,01 & 26,72 & 113,13 \\
\hline Produtividade $\left(\mathrm{g} \mathrm{m}^{-2}\right)$ & 1,74 & 3,36 & 2,48 \\
\hline
\end{tabular}


A saturação por bases (V) apresentou valores muito inferiores a $50 \%$, e a saturação por $\mathrm{Al}(\mathrm{m})$, maior que $50 \%$, caracterizando os solos como distróficos e álicos. O teor de $\mathrm{P}$ também foi baixo, semelhante aos encontrados por Silva et al. (2010) em solos dessa região do Jalapão. Nesse segmento, a produtividade do capim dourado foi a mais baixa, com $1,74 \mathrm{~g} \mathrm{~m}^{-2}$. Essa menor produtividade pode ser explicada pela baixa umidade do solo (Quadro 1). Segundo Oliveira et al. (2010), os baixos teores de umidade no solo não propiciam condições favoráveis para a absorção dos nutrientes, que se dá por fluxo de massa ou difusão.

\section{Segmento S2 das transeções}

Os solos apresentaram textura arenosa, com o teor de areia total em torno de 946,00 $\mathrm{g} \mathrm{kg}^{-1}$ e com $53,99 \mathrm{~g} \mathrm{~kg}^{-1}$ de soma dos teores de argila e silte, sendo classificados como Neossolos Quartzarênicos hidromórficos típicos (Embrapa, 2013). Nesse segmento, foram encontrados os menores e os maiores teores de areia fina e areia grossa, respectivamente, dentre os três segmentos avaliados. A Ds evidenciou valor mediano entre as densidades dos solos nos segmentos $\mathrm{S} 1$ e $\mathrm{S} 3$, com valor de $1,09 \mathrm{~kg} \mathrm{dm}^{-3}$. O relevo também se enquadrou na classe de suave ondulado (5,36\% de declividade).

$\mathrm{O}$ valor do $\mathrm{pH}$ foi baixo, menor que em $\mathrm{S} 1$; entretanto, continuou sendo classificado como medianamente ácido. $\mathrm{O}$ teor de $\mathrm{Al}^{3+}$ teve acréscimo, traduzindo-se em maior acidez potencial $(\mathrm{H}+\mathrm{Al})$ em relação aos valores encontrados nos solos em S1. A soma de bases continuou baixa, o que implicou em teores de $\mathrm{V}$ muito inferiores a $50 \%$ e teor de m superior a $50 \%$, ou seja, os solos são distróficos e álicos.

Em relação ao teor de $\mathrm{P}$, houve pequeno acréscimo em relação aos solos em S1. Já o teor de CO, teve aumento considerável em relação aos solos em S1 (Quadro 1). O acúmulo de material orgânico foi, provavelmente, ocasionado pelo ambiente anaeróbico nesse segmento, que, ao final da época da seca, atingiu valores médios de umidade de $0,40 \mathrm{~cm}^{3} \mathrm{~cm}^{-3}$. Esse alto teor de umidade, no final da época seca, pode indicar que nesse ambiente ocorra saturação do solo na época das chuvas, pois ocupa o terço médio da transeção, uma vez que o ambiente hidromórfico é caracterizado por saturação permanente ou periodicamente (Embrapa, 2013).

A produtividade do capim dourado foi a mais elevada nesse segmento em relação aos demais, atingindo $3,36 \mathrm{~g} \mathrm{~m}^{-2}$. A sua alta produtividade pode ser explicada pela umidade encontrada, o que propiciou as condições mais favoráveis ao desenvolvimento e à produção de escapos da espécie em relação aos segmentos $\mathrm{S} 1$ e S3. Segundo Schmidt et al. (2008), a emissão dos escapos ocorre nos meses de abril e maio; sua floração inicia-se a partir de julho. Nos meses de abril e maio, inicia-se o período em que cessam as chuvas na região do Jalapão e começa a época da seca.

\section{Segmento S3 das transeções}

A textura do solo nesse segmento se enquadrou em areia franca, com teor de areia total em torno de $795,00 \mathrm{~g} \mathrm{~kg}^{-1}$ e com teores de argila e silte de 95,33 e 109,66 $\mathrm{g} \mathrm{kg}^{-1}$, respectivamente. Os solos foram classificados como Organossolos Háplicos fíbricos típicos (Embrapa, 2013). O teor de areia grossa foi o menor em relação a S1 e S2 (Quadro 1). Em S3, foi encontrada a maior umidade no solo $\left(0,73 \mathrm{~cm}^{3} \mathrm{~cm}^{-3}\right)$; nessa região, o solo se encontra saturado, em razão da sua posição mais baixa no relevo em relação aos segmentos anteriores, aliada à proximidade com o curso d'água. A Ds foi a menor $\left(0,33 \mathrm{~kg} \mathrm{dm}^{-3}\right)$ entre os segmentos avaliados, uma vez que essa diminui com o incremento de MO, em razão da baixa densidade da $\mathrm{MO}$ em relação à fração mineral do solo (Araújo et al., 2007; Valladares, 2008). Esse valor de Ds está dentro da amplitude encontradao por Valladares et al. (2008), em estudo sobre Organossolos e solos afins. A declividade atingiu 5,42\%, continuando na mesma classe de relevo dos demais segmentos (suave ondulado).

Nesse segmento, o solo apresentou o mais baixo valor de $\mathrm{pH}\left(\mathrm{H}_{2} \mathrm{O}\right)$, mas permaneceu classificado como medianamente ácido. $\mathrm{O} \mathrm{Al}^{3+}$ teve acréscimo considerável em relação aos solos em S1 e S2, refletindo aumento na acidez potencial $(\mathrm{H}+\mathrm{Al})$, provavelmente por causa do aumento de CO. A diminuição dos valores de $\mathrm{pH}\left(\mathrm{H}_{2} \mathrm{O}\right)$ e $\mathrm{V}$ se deve ao maior teor de $\mathrm{CO}$ no solo, pois no processo de mineralização e formação de substâncias húmicas há a liberação de nitratos e íons $\mathrm{H}^{+}$na solução do solo (Meurer, 2006). A soma de bases (S) continuou baixa, o que implicou em baixos teores de V $(<50 \%)$ e elevado teor de $\mathrm{m}(>50 \%)$, classificando-se como solos distróficos e álicos. Ocorreu aumento nos teores de $\mathrm{T}$ em relação aos solos em $\mathrm{S} 1$ e $\mathrm{S} 2$, possivelmente em razão do aumento no teor de CO. Nesse ambiente, foi detectado acúmulo de material orgânico originado de ambiente anaeróbico com umidade elevada, com teor de CO maior que $80,0 \mathrm{~g} \mathrm{~kg}^{-1}$, configurando-se como solos com predomínio de material orgânico. $\mathrm{O}$ teor de CO encontrado nesse segmento $\left(113,13 \mathrm{~g} \mathrm{~kg}^{-1}\right)$ está próximo ao intervalo encontrado por Ebeling et al. (2011), que obtiveram valores entre 116,66 e $745,83 \mathrm{~g} \mathrm{~kg}^{-1}$ em Organossolos de diversas regiões do Brasil. Os autores atribuíram a variabilidade em decorrência da cobertura vegetal, do clima e da umidade ao longo do tempo. Em geral, os Organossolos apresentam características como elevada acidez e baixa saturação por bases (Ebeling et al., 2008; Valladares, 2008), como verificado neste trabalho. Foi constatado aumento no teor de $\mathrm{P}$ em relação aos teores encontrados em 
S1 e S2, com valores superiores aos encontrados por Silva et al. (2010) em Veredas da região do Jalapão, possivelmente associado ao incremento de CO. A produtividade do capim dourado foi intermediária $\left(2,48 \mathrm{~g} \mathrm{~m}^{-2}\right)$, em relação aos segmentos $\mathrm{S} 1$ e S2, o que deve estar associado à saturação de água do solo.

\section{Comportamento das variáveis ao longo dos Segmentos S1, S2 e S3}

As médias dos resultados das variáveis avaliadas nas 10 Veredas do PEJ evidenciaram que, para os segmentos S1, S2 e S3, os valores obtidos foram crescentes para $\mathrm{K}^{+}, \mathrm{Mg}^{2+}, \mathrm{Ca}^{2+}, \mathrm{P}, \mathrm{CO}, \mathrm{S}, \mathrm{T}, \mathrm{Al}^{3+}$, $\mathrm{H}+\mathrm{Al}, \mathrm{t}, \mathrm{m}$, argila, silte, umidade e declividade no sentido de $\mathrm{S} 1$ para S3. Já os valores de $\mathrm{pH}, \mathrm{V}$, areia total e Ds apresentaram decréscimo.

Já a produtividade do capim dourado apresentou teores maiores em S2.

\section{Relação entre atributos dos solos e a produtividade do capim dourado}

Os resultados da análise da regressão quadrática múltipla entre a produtividade de escapos de capim dourado e as variáveis independentes indicaram que o modelo adotado foi estatisticamente significativo, melhorando com a retirada de uma amostra considerada outlier. A variabilidade explicada pelo modelo (soma dos quadrados do modelo - $\mathrm{SS}_{\mathrm{M}}$ ) foi de 11,815 , e a variabilidade não explicada (soma dos quadrados dos resíduos - $\mathrm{SS}_{\mathrm{R}}$ ) foi de 2,121, correspondendo a uma variação total $\left(\mathrm{SS}_{\mathrm{T}}\right)$ de 13,935. A comparação entre a média dos quadrados da regressão $\left(\mathrm{MQ}_{\mathrm{M}}=1,969\right)$ e a média dos quadrados dos resíduos $\left(\mathrm{MQ}_{\mathrm{R}}=0,096\right)$ confirmou que as variações na produtividade não são consequência do acaso (resíduos) e podem ser explicadas pelas diferenças existentes entre os valores das variáveis independentes incluídas no modelo.

A análise de variância apresentou valor de $\mathrm{F}=20,429$ (significativo a $\mathrm{p}<0,001$ ), aceitando-se a hipótese de que existe relação linear entre a variável dependente em pelo menos uma das variáveis independentes, ou seja, existe relação de causa-efeito entre a variável dependente e as independentes. $\mathrm{O}$ modelo apresentou valor de $\mathrm{R}^{2}$ de 0,85 e $\mathrm{R}^{2}$ ajustado de 0,81 .

Mediante processo de redução do número de variáveis independentes a serem consideradas no modelo, utilizando o método backward, o teste t a $5 \%$ de significância selecionou as variáveis $\mathrm{pH}\left(\mathrm{x}_{1}\right)^{2}, \mathrm{Mg}^{2+}\left(\mathrm{x}_{2}\right)^{2}, \mathrm{Ca}^{2+}\left(\mathrm{x}_{3}\right)^{2}$, areia fina - $\mathrm{AF}$ $\left(\mathrm{x}_{4}\right)^{2}$, argila $\left(\mathrm{x}_{5}\right)$ e umidade $\left(\mathrm{x}_{6}\right)$. As estimativas dos coeficientes das variáveis independentes e do intercepto para o modelo de regressão quadrática múltipla encontram-se no quadro 2.

Dos coeficientes estimados, apenas o intercepto $\mathrm{X}_{0}$ (valor da variável dependente quando todas as variáveis independentes são iguais a zero) e a umidade apresentaram interação positiva com a produtividade de escapos. $\mathrm{O}$ coeficiente argila $\left(\mathrm{x}_{5}\right)$ evidenciou interação negativa, e as demais variáveis apresentaram interações quadráticas; os valores dos coeficientes são negativos.

Essas interações explicam a adaptação do capim dourado ao ambiente natural de ocorrência do bioma Cerrado no Jalapão, uma espécie nativa em Campo Limpos Úmidos associados às Veredas. Essas interações corroboram o estudo de Haridasan (2008), o qual constatou que espécies nativas que ocorrem nesse bioma são resistentes e tolerantes às condições edáficas consideradas desfavoráveis às plantas cultivadas, mas sua distribuição e frequência nas comunidades nativas, crescimento e produtividade são determinados pela disponibilidade de nutrientes, regime hídrico do solo e outros fatores edáficos.

O ambiente de ocorrência do capim dourado apresentou solos medianamente ácidos e distróficos, que não influenciaram o seu desenvolvimento, concordando com Haridasan (2008). Entretanto, o

Quadro 2. Coeficientes estimados e padronizados relativos ao teste $t$, no intervalo de confiança de $95 \%$ e fator inflação da variância (VIF) para os coeficientes da regressão quadrática múltipla para a produtividade de capim dourado nos Campos Limpos Úmidos associados às Veredas avaliadas do Parque Estadual do Jalapão, Tocantins

\begin{tabular}{|c|c|c|c|c|c|c|c|c|}
\hline \multirow{3}{*}{ Variável } & \multicolumn{3}{|c|}{ Coeficiente } & \multirow{3}{*}{ Teste $t$} & \multirow{3}{*}{ Sig. } & \multirow{2}{*}{\multicolumn{2}{|c|}{$\begin{array}{c}\text { Intervalo de confiança de } 95 \% \text { para } \beta \\
\text { Limite }\end{array}$}} & \multirow{3}{*}{ VIF } \\
\hline & \multicolumn{2}{|c|}{ Não padronizado } & \multirow{2}{*}{$\frac{\text { Padronizado }}{\beta}$} & & & & & \\
\hline & $\boldsymbol{\beta}$ & Erro-padrão & & & & Inferior & Superior & \\
\hline $\mathrm{X}_{0}=$ intercepto & 6,38 & 1,42 & & 4,48 & 0,00 & 3,43 & 9,34 & \\
\hline$\left(\mathrm{x}_{1}\right)^{2}=\mathrm{pH} \times \mathrm{pH}$ & $-0,12$ & 0,04 & $-0,31$ & $-2,65$ & 0,01 & $-0,21$ & $-0,03$ & 2,01 \\
\hline$\left(\mathrm{x}_{2}\right)^{2}=\mathrm{Mg} \times \mathrm{Mg}$ & $-9,46$ & 1,73 & $-0,70$ & $-5,46$ & 0,00 & $-13,06$ & $-5,87$ & 2,40 \\
\hline$\left(\mathrm{x}_{3}\right)^{2}=\mathrm{Ca} \times \mathrm{Ca}$ & $-13,47$ & 4,35 & $-0,42$ & $-3,10$ & 0,01 & $-22,49$ & $-4,45$ & 2,68 \\
\hline$\left(\mathrm{x}_{4}\right)^{2}=\mathrm{AF} \times \mathrm{AF}$ & $-2,71 \times 10^{-6}$ & 0,00 & $-0,61$ & $-5,40$ & 0,00 & 0,00 & 0,00 & 1,86 \\
\hline$\left(x_{5}\right)=$ Argila & $-0,01$ & 0,00 & $-0,645$ & $-3,67$ & 0,00 & $-0,02$ & $-0,00$ & 4,52 \\
\hline$\left(\mathrm{x}_{6}\right)=$ Umidade & 1,94 & 0,47 & 0,81 & 4,13 & 0,00 & 0,96 & 2,91 & 5,54 \\
\hline
\end{tabular}

Variável dependente: $\ln$ (produtividade); AF: areia fina; e Sig.: significância. 
capim dourado é uma espécie exigente em teor de água no solo.

De acordo com Haridasan (2008), algumas espécies nativas do bioma Cerrado crescem em solos ácidos e são tolerantes ou resistentes ao $\mathrm{Al}$, porque sua capacidade de absorção de nutrientes essenciais, crescimento e reprodução não são prejudicados pelas altas concentrações de $\mathrm{Al}$ no solo. Esse fato é observado pela elevação da saturação por $\mathrm{Al}$ do $\mathrm{S} 1$ em relação ao $\mathrm{S} 2$ e mesmo assim a produtividade teve acréscimo próximo a $100 \%$. O mesmo é comprovado pelo fato de $\mathrm{m}$ não fazer parte da equação que explica a relação entre atributos físicos e químicos do solo e a produtividade de capim dourado.

Todos os coeficientes de regressão foram significativos $(\mathrm{p}<0,05)$, aceitando-se a hipótese de existência de uma relação linear significativa entre as variáveis independentes consideradas no modelo na contribuição da variável dependente (produtividade) (Quadro 2).

Os coeficientes de $B$ padronizados são todos mensurados em termos de unidades de desviospadrão e são diretamente comparáveis; a maior contribuição das variáveis independentes no modelo foi dada pela umidade, seguida por $\mathrm{pH}$, $\mathrm{Ca}$, areia fina, argila e $\mathrm{Mg}$. $\mathrm{O}$ fator inflação da variância (VIF) encontrado no modelo para as variáveis independentes está de acordo com Mayers (2000), o qual sugeriu que a partir de 10 é um valor preocupante.

Assim, o modelo de regressão quadrática múltipla ajustado para a produtividade de capim dourado encontra-se apresentada na equação 1 :

$\hat{y}=\left(e^{\left(6,389-(0,116) x_{1}^{2}-(9,464) x_{2}^{2}-(13,470) x_{3}^{2}-(2,712 \mathrm{E}-6) x_{4}^{2}-(0,009) x_{5}+(1,935) x_{6}\right)}\right)-1$

Eq. 1

Sendo $\hat{\mathrm{y}}$ : produtividade estimada; $e$ : expoente; $\left(\mathrm{x}_{0}\right)=6,383$ (intercepto); $\left(\mathrm{x}_{1}\right)^{2}=-0,116(\mathrm{pH} \times \mathrm{pH}) ;$ $\left(\mathrm{x}_{2}\right)^{2}=-9,464(\mathrm{Mg} \times \mathrm{Mg}) ;\left(\mathrm{x}_{3}\right)^{2}=-13,470(\mathrm{Ca} \times \mathrm{Ca}) ;$ $\left(\mathrm{x}_{4}\right)^{2}=-2,712 \times 10-6(\mathrm{AF} \times \mathrm{AF}) ;\left(\mathrm{x}_{5}\right)=-0,009$ (Argila); e $\left(\mathrm{x}_{6}\right)=1,935$ (Umidade).

A dispersão dos 29 valores estimados e observados da produtividade do capim dourado no PEJ é evidenciada na figura 2 , cuja média calculada por segmento encontra-se no quadro 1.

$\mathrm{O}$ valor de $\mathrm{r}=0,84$ indicou que a estimativa da produtividade pelo modelo proposto foi boa. A exatidão, representada pelo índice $d=0,91$, demonstrou que o modelo foi capaz de estimar a produtividade de capim dourado com relativa exatidão. $\mathrm{O}$ desempenho do modelo, representado pelo valor de $\mathrm{c}=0,77$, é interpretado como muito boa, segundo o critério proposto por Camargo e Sentelhas (1997).

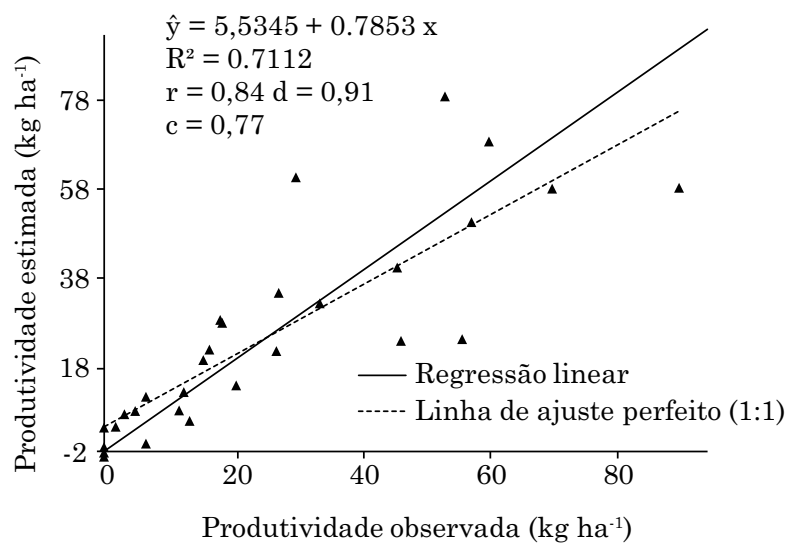

Figura 2. Diagrama de dispersão das amostras da produtividade do capim dourado observada (eixo X) e a estimada (eixo Y) estabelecida pelo modelo proposto para o Parque Estadual do Jalapão. $\left(R^{2}\right.$ : coeficiente de determinação; $r$ : coeficiente de correlação de Pearson; d: coeficiente de Willmott; e c: índice de desempenho).

\section{CONCLUSÕES}

A produtividade de capim dourado do PEJ possui interação com os seguintes atributos do solo: $\mathrm{pH}\left(\mathrm{H}_{2} \mathrm{O}\right), \mathrm{Mg}^{2+}, \mathrm{Ca}^{2+}$, areia fina, argila e umidade.

A umidade do solo foi a variável mais importante no modelo de regressão quadrática múltipla estabelecida para a produtividade do capim dourado no PEJ no estádio de maturação dessa espécie, ou seja, na época propícia para a coleta de escapos.

\section{REFERÊNCIAS}

Araújo R, Goebert WJ, Lacerda MPC. Qualidade de um solo sob diferentes usos e sob cerrado nativo. R Bras Ci Solo. 2007;31:1099-108.

Bayer C, Mielniczuk J, Martin-Neto L. Efeitos de sistemas de preparo e de cultura na dinâmica da matéria orgânica e na mitigação das emissões $\mathrm{CO}_{2}$. R Bras Ci Solo. 2000;24:559-607.

Caetano JO; Benites VM, Silva GP, Silva IR, Assis RL, C Filho A. Dinâmica da matéria orgânica de um Neossolo Quartzarênico de cerrado convertido para cultivo em sucessão de soja e milheto. R Bras Ci Solo. 2013;37:1245-55.

Camargo AP, Sentelhas PC. Avaliação de desempenho de diferentes métodos de estimativa da evapotranspiração potencial no Estado de São Paulo, Brasil. R Bras Agrometeorol. 1997;5:89-97.

Carvalho PGS. As veredas e sua importância no domínio dos cerrados. Inf Agropec. 1991;15:54-6.

Empresa Brasileira de Pesquisa Agropecuária - Embrapa. Sistema brasileiro de classificação de solos. $3^{a}$.ed. Brasília: Embrapa Solos; 2013. 
Empresa Brasileira de Pesquisa Agropecuária - Embrapa. Centro Nacional de Pesquisa de Solo. Manual de métodos de análise de solos. Rio de Janeiro: 1997.

Giulietti AM, Wanderley MGL, Longhi-Wagner HM, Pirani JR, Parra LR. Estudos em "sempre vivas": Taxonomia com ênfase nas espécies de Minas Gerais, Brasil. Acta Bot Bras. 1996;10:329-83.

Guimarães AJ, Araújo GM, Correira GF. Estrutura fitossociológica em área natural e antropizada de uma vereda em Uberlândia, MG. Acta Bot Bras. 2002;16:317-29.

Haridasan M. Nutritional adaptations of native plants of the cerrado biome and acid soils. Braz J Plant Physiol. 2008;20:183-95.

Instituto Natureza do Tocantins. Naturatins. Levantamento aerofotogramétrico, na escala 1:25.000, do Parque Estadual do Jalapão. Projeto AASA 92/2002. Curitiba: Aeroimagem; 2002.

Instituto Natureza do Tocantins. Naturatins. Portaria 362/2007 que adota medidas de ordenamento à coleta e ao manejo do capim dourado. Palmas: 2007.

Lúcio ADC, Couto MRM, Lopes SJ, Storck L. Transformação Box-Cox em experimentos com pimentão em ambiente protegido. Hortic Bras. 2011;29:38-42.

Lúcio ADC, Couto MRM, Trevisan JN, Martins GAK, Lopes SJ. Excesso de zeros nas variáveis observadas: Estudo de caso em experimento com brócolis. Bragantia. 2010;69:1035-46.

Mayers RH. Classical and modern regression with applications. $2^{\text {nd }}$. ed. Boston: Duxbury Classic; 2000.

Mesquita MAM, Naves RV, Souza EB, Bernardes TG, Silva LBE. Caracterização de ambientes com alta ocorrência natural de araticum (Annona crassiflora Mart.) no estado de Goiás. R Bras Frutic. 2007;29:15-9.

Meurer EJ. Fundamentos de química do solo. $3^{\text {a }}$.ed. Porto Alegre: Evangraf; 2006.

Munhoz CBR, Felfile JM. Florística do estrato herbáceo-subarbustivo de um Campo Limpo Úmido em Brasília, Brasil. Biota Neotrop. 2007;7:205-15.

Oliveira EMM, Ruiz HA, Alvarez V VH, Ferreira PA, Costa FO, Almeida ICC. Nutrient supply by mass flow and diffusion to maize plants in response to soli aggregate size and water potential. $\mathrm{R}$ Bras Ci Solo. 2010;34:317-27.

Pacifico M, Napolitano A, Masullo M, Hilario F, Vilegas W, Piacente S, Santos LC. Metabolite fingerprint of "capim dourado" (Syngonanthus nitens), a basis of Brazilian handcrafts. Ind. Crops Produc. 2011;33:488-96.

Ramos MVV, Curi N, Mota PEF, Vitorino ACT, Ferreira MN, Silva MLN. Veredas do Triângulo Mineiro: solos, água e uso. Ci Agrotec. 2006;30:283-93.
Sano EE, Rosa R, Brito JLS, Ferreira LG. Mapeamento semidetalhado do uso da terra do bioma Cerrado (notas científicas). Pesq Agropec Bras. 2008;43:153-6.

Sano SM, Simon MF. Produtividade do baru (Dipteryx alata Vong.) em ambientes modificados, durante 10 anos. In: Anais do $9^{\circ}$ Simpósio Nacional do Cerrado, 2008; Brasília. Planaltina: Embrapa Cerrados; 2008.

Santana HMP, Lacerda MPC, Barros MA, Barbosa IO. Unidades pedoambientais da região de Santa Tereza, estado do TO. Pesq Agropec Trop. 2010;40:8-19.

Santana HMP, Sano EE, Lacerda MPC. Levantamento dos campos limpos úmidos no Parque Estadual do Jalapão, TO, por meio de fotografias aéreas analógicas: Abordagem metodológica. R Bras Cartogr. 2014;66:71-81.

Santiago AR, Pereira Júnior AC. Mapeamento da cobertura da terra dos Parques Estaduais do Jalapão (PEC), Cantão (PEC) e município de Itaguatins (Tocantins). Ambiência. 2010;6:109-24.

Schmidt IB, Figueiredo IB, Borghetti F, Scariot A. Produção e germinação de sementes de "capim dourado" Syngonanthus nitens (Bong.) Ruland (Euriocaulaceae): Implicações para o manejo. Acta Bot Bras. 2008;22:37-42.

Schmidt IB, Figueiredo IB, Scariot A. Ethnobotany and efects of harvesting on the population ecology of Syngonanthus nitens (Bong.) Ruland (Euriocaulaceae), a NTFP from Jalapão region, central Brazil. Econ Bot. 2007;61:73-85.

Schmidt IB, Mandle L, Ticktin T, Gaoue O. What do matrix population models reveal about the sustainability of non-timber forest product harvest? J Appl Ecol. 2011;48:815-26.

Schmidt IB, Ticktin T. When lessons from population models and local ecological knowledge coincide - Effects of flower stalk harvesting in the Brazilian savanna. Biol Conserv. 2012;152:187-95.

Secretaria de Planejamento e da Gestão Pública - Seplan. Atlas do Tocantins: Subsídios ao planejamento da gestão territorial. Palmas: 2012.

Silva RB, Santos AC, Silva JEC, Oliveira OBT, Aráujo AS. Diagnóstico do solo em áreas de ocorrência de capim dourado na região do Jalapão, estado do Tocantins. Amazônia: Ci Desenv. 2010;6:91-101.

Statistical Package for Social Sciences. SSPS - Release 19.0 for Windows. Chicago: 2008.

Valladares GS, Gomes EG, Mello JCCBS, Pereira MG, Anjos LHC, Ebeling AG, Benites VM. Análise dos componentes principais e métodos multicritérios de estudo de Organossolos e solos afins. R Bras Ci Solo. 2008;32:285-96.

Valladares SG. Caracterização de solos brasileiros com elevados teores de material orgânico. Magistra. 2008;20:95-104.

Willmott CT. Some comments on the evaluation of model performance. Bull Am Meteorol Soc. 1982;63:1309-13. 